\title{
Lake Baikal deepwater renewal mystery solved
}

\author{
Martin Schmid, ${ }^{1}$ Nikolay M. Budnev, ${ }^{2}$ Nick G. Granin, ${ }^{3}$ Michael Sturm, ${ }^{1}$ \\ Michael Schurter, ${ }^{1}$ and Alfred Wüest ${ }^{1,4}$ \\ Received 9 January 2008; revised 7 March 2008; accepted 7 April 2008; published 9 May 2008.
}

[1] Deepwater renewal by intrusions and turbulent diffusion in Lake Baikal is very effective despite the enormous depth of up to $1642 \mathrm{~m}$ and the permanently stable stratification below $\sim 300 \mathrm{~m}$ depth. Temperature time series recorded at the bottom of a mooring installed since March 2000 in the South Basin of the lake indicate recurrent freshwater intrusions with volumes of 50 to $100 \mathrm{~km}^{3}$, about one order of magnitude larger than previously observed intrusions. Numerous mechanisms have been proposed to explain the advective deep water renewal. Here we present for the first time direct observations which prove that they are caused by coastal downwelling and subsequent thermobaric instability along the steep lake shores. Understanding these mechanisms is an important prerequisite for studying biogeochemical cycles, for predicting the effects of climate change on this unique ecosystem and for evaluating the local climate history from the extraordinary sedimentary record of Lake Baikal. Citation: Schmid, M., N. M. Budnev, N. G. Granin, M. Sturm, M. Schurter, and A. Wüest (2008), Lake Baikal deepwater renewal mystery solved, Geophys. Res. Lett., 35, L09605, doi:10.1029/ 2008 GL033223.

\section{Introduction}

[2] Lake Baikal is one of the most unusual lakes in the world. It is the world's largest reservoir of fresh surface water and home to several hundred endemic species [Kozhova and Izmesteva, 1998]. The lake is divided into three basins of similar size the deepest of which is the Central Basin (CB, $1642 \mathrm{~m}$ ), followed by the South Basin (SB, $1461 \mathrm{~m}$ ) and the North Basin (NB, $904 \mathrm{~m})$.

[3] Seasonal convective mixing cannot reach beneath $\sim 300 \mathrm{~m}$ depth due to the effect of pressure on the temperature of maximum density (TMD). The TMD decreases by $\sim 0.2^{\circ} \mathrm{C}$ per $100 \mathrm{~m}$ depth, varying from $4^{\circ} \mathrm{C}$ at the surface to $<1^{\circ} \mathrm{C}$ in the depths of the $\mathrm{CB}$. The deep water of the lake, below $300 \mathrm{~m}$ depth, is weakly but permanently stratified by temperature [e.g., Weiss et al., 1991]. Hence, one would expect geothermal heat input and warming from above to destroy this stratification, but the gradient and thus the permanent stratification is maintained by regularly occurring deep inputs of cold surface water.

\footnotetext{
${ }^{1}$ Swiss Federal Institute of Aquatic Science and Technology (Eawag), Kastanienbaum, Switzerland.

${ }^{2}$ Applied Physics Institute, Irkutsk State University, Irkutsk, Russia.

${ }^{3}$ Limnological Institute of the Siberian Division of the Russian Academy of Sciences, Irkutsk, Russia.

${ }^{4}$ Institute of Biogeochemistry and Pollutant Dynamics, ETH Zurich, Zurich, Switzerland.
}

Copyright 2008 by the American Geophysical Union. 0094-8276/08/2008GL033223\$05.00
[4] The high deepwater renewal rate has important consequences. It leads to efficient recycling of the nutrients from the deep water which is on the same order of magnitude as the external nutrient inputs [Müller et al., 2005]. As a result both biological and biogeochemical processes in the lake depend on the vertical exchange mechanisms.

[5] To be able to predict changes in the deepwater renewal rates in a changing environment, it is essential to understand the underlying mechanisms. Recent changes like the shortening of the ice-covered period [Todd and Mackay, 2003] or the weakening of the typical winter Siberian high pressure system [Panagiotopoulos et al., 2005] could affect vertical mixing processes and deepwater renewal. Furthermore, understanding these processes is an important step towards evaluating historic changes in the biological productivity and diversity observed in the unique sediment stratigraphy [Mackay, 2007].

[6] Several studies have shown that the effective deepwater renewal is due to both a very high vertical diffusivity (on the order of $10^{-3} \mathrm{~m}^{2} \mathrm{~s}^{-1}$ within the very weakly stratified deep water), and an advective flux of surface water down to the depths of the individual basins [e.g., Kipfer et al., 2000]. Especially in the SB, deep cold water intrusions have been regularly observed, usually around the time of convective surface mixing in June and December/ January [Wüest et al., 2005].

[7] Different mechanisms have been put forward to explain the deepwater intrusions. For example, it has been suggested that density plumes formed from the slightly harder and therefore denser water of the Selenga River plunge down to the depths of the $\mathrm{CB}$ and possibly also the $\mathrm{SB}$ in the spring [Hohmann et al., 1997], or that thermal bars form due to the mixing of pelagic water colder than the TMD with near-shore water warmer than the TMD [Shimaraev et $a l ., 1993]$. It has also been proposed that during periods of weak stratification, surface water with a temperature below the bottom water temperature could be pushed down to a depth where its density is higher than that of the ambient water at the same depth [Weiss et al., 1991]. Given a typical temperature stratification in the SB in June or December (Figure 1), the water would have to be vertically displaced by $\sim 200 \mathrm{~m}$ until its temperature difference to the TMD is lower than that of the ambient water. In this case thermobaric instabilities would occur and the water would plunge to the deepest reaches of the SB. The required vertical displacement and the energy needed to achieve it increase with decreasing surface temperature. Thermobaric instabilities are therefore most probable when the surface water is just slightly colder than the deep water, which is the case before convective mixing (by warming) in June and after convective mixing (by cooling) in December or January. 


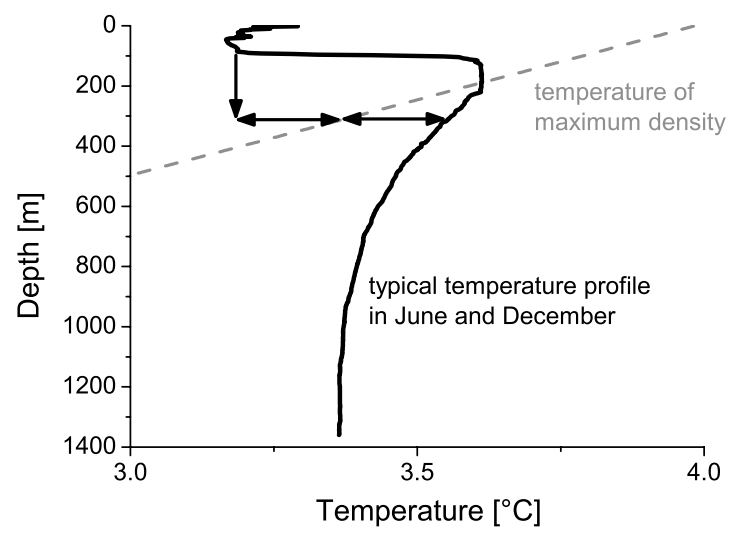

Figure 1. A vertical temperature profile in the SB of Lake Baikal as it is usually observed at the beginning of June or at the end of December, and temperature of maximum density as a function of depth. The profile shown here for example was measured on 6 June 2000. The vertical arrow indicates the minimum displacement of surface water required to reach a depth where its temperature difference to the TMD is smaller than that of the ambient water at the same depth (indicated by the horizontal arrows).

[8] Both calculations with a two-dimensional model [Akimoto et al., 1995] as well as rough estimates based on the underlying physical processes [Wüest et al., 2005] suggested that an along-shore wind on the order of some $6 \mathrm{~m} \mathrm{~s}^{-1}$ could produce a sufficiently strong Ekman transport towards the shore to cause the required downwelling. Such wind speeds at that time of the year are common at Lake Baikal [Shimaraev et al., 1994]. But temperatures of thermistors moored at different locations in the pelagic waters have never shown downwelling sufficient to produce thermobaric instabilities. We therefore hypothesized that previous moorings had been located too far offshore. Starting in March 2004, we deployed the mooring "Shore" at a distance of $\sim 1.0 \mathrm{~km}$ from the northern shore of the SB, in addition to the two moorings "Neutrino West" (NTW) and "Neutrino East" (NTE) that had already been installed further offshore (Figure 2). This setup allowed us to observe for the first time a coastal downwelling event in Lake Baikal leading to a large deepwater intrusion.

\section{Methods}

[9] Three moorings were installed near the northern shore of the SB from March 2004 to March 2007: The moorings NTW and NTE were situated at a distance of $3.2 \mathrm{~km}$ from the shore, separated by $1.0 \mathrm{~km}$, at a depth of $\sim 1350 \mathrm{~m}$. The third mooring "Shore" was placed on a small flat area within the steeply descending slope, at a depth of $550 \mathrm{~m}$, $1.0 \mathrm{~km}$ from the shore (Figure 2).

[10] The moorings were equipped with different types of thermistors: Vemco 12-bit minilog $64 \mathrm{~K}$ (resolution $0.015^{\circ} \mathrm{C}$, accuracy $0.1{ }^{\circ} \mathrm{C}$ ), RBR TR-1000 (resolution $0.002^{\circ} \mathrm{C}$, accuracy $0.05^{\circ} \mathrm{C}$ ), TR-1050 (resolution $0.0001^{\circ} \mathrm{C}$, accuracy $0.002^{\circ} \mathrm{C}$ ), and TDR-2050 (resolution $0.0001^{\circ} \mathrm{C}$, accuracy $0.002^{\circ} \mathrm{C}$ ). In addition, two Aanderaa current meters RCM7 (resolution $0.007 \mathrm{~m} \mathrm{~s}^{-1}$, accuracy $0.01 \mathrm{~m} \mathrm{~s}^{-1}$, threshold $0.02 \mathrm{~m} \mathrm{~s}^{-1}$ ), were installed. The data were retrieved once every year in March. For the time period from March 2006 to March 2007, which is investigated in more detail below, the moorings were configured as follows:

[11] NTW: Vemco minilog at 11, 50, 100, 150 and $250 \mathrm{~m}$ depth, TR- 1050 at $75,125,400,500$ and $1250 \mathrm{~m}$ depth, TR1000 at $300,1000,1300,1330$, and $1350 \mathrm{~m} \mathrm{(2} \mathrm{m} \mathrm{above}$ ground) depth, TDR-2050 at $700 \mathrm{~m}$ depth. This mooring had been installed in the lake with varying configurations since March 2000.

[12] NTE: Vemco minilog at 17, 32, 56, 70, 85 and $104 \mathrm{~m}$ depth, TR-1000 at 794, 1294, 1334, and $1353 \mathrm{~m}$ depth $(2 \mathrm{~m}$ above ground), TR-1050 at $379 \mathrm{~m}$ depth, and TDR-2050 at $994 \mathrm{~m}$ depth.

[13] "Shore": Vemco minilog at 15, 50 100, 150, 200, 250 and $300 \mathrm{~m}$ depth, TR-1000 at 400, 450, 500, and $547 \mathrm{~m}$ (3 $\mathrm{m}$ above ground) depth, TR-1050 at $525 \mathrm{~m}$ depth, Aanderaa current meters at 16 and $548 \mathrm{~m}$ depth.

[14] The accuracy of the thermistors was confirmed in the laboratory before deployment using a 7025 Benchtop Calibration Bath (Hart Scientific). The sensors were calibrated using an automated temperature stepping program. This allowed the RBR sensor-to-sensor differences to be reduced to approximately $0.001^{\circ} \mathrm{C}$. Vemco thermistors were only deployed at depths where the temperature variability is so high that their lower resolution and accuracy is not important.

[15] Vertical temperature and conductivity (CTD) profiles were regularly measured at several locations in the SB using a Sea-Bird SBE 25 Sealogger CTD probe. Wind speed and direction were measured using an ultrasonic anemometer (precision $0.15 \mathrm{~m} \mathrm{~s}^{-1}$ for wind speed and $3^{\circ}$ for wind direction) uphill of the village of Listvyanka at $208 \mathrm{~m}$ above the lake level and $4.5 \mathrm{~m}$ above ground, $\sim 34 \mathrm{~km}$ northeast of the moorings (Figure 2).

\section{Results and Discussion}

[16] Six large cold water intrusions were observed at the bottom of the NTW mooring between March 2000 and March 2007 (Figure 3). Four of them occurred in December/ January and one in mid-June, i.e., at times when the conditions for the formation of thermobaric instabilities are ideal. One intrusion was observed in February 2006 when the lake would normally be ice-covered. However, in 2006 the SB was at least partially open in February. Both the large-scale trends and the short-term temporal dynamics of the temperatures observed at the bottom of the NTE mooring (not shown) were usually very similar to those observed at the NTW mooring, however typically with time shifts of a few hours to one day. The observed intrusions were thus of a significantly larger scale than the $1 \mathrm{~km}$ distance between the two moorings.

[17] The intruding water masses were 0.1 to $0.35^{\circ} \mathrm{C}$ colder than the ambient deep water which has a background temperature of $\sim 3.38^{\circ} \mathrm{C}$. After each cooling event the temperature $2 \mathrm{~m}$ above bottom at the NTW mooring exponentially approached $3.38^{\circ} \mathrm{C}$ with an e-folding time constant of 4 to 6 months. This time scale agrees well with the previously estimated vertical diffusivity on the order of $10^{-3} \mathrm{~m}^{2} \mathrm{~s}^{-1}$ in the deep water [Wüest and Lorke, 2003]. The total heat input between 1300 and $1400 \mathrm{~m}$ depth was estimated based on the temperature difference between CTD profiles observed in the middle of the SB in October and 


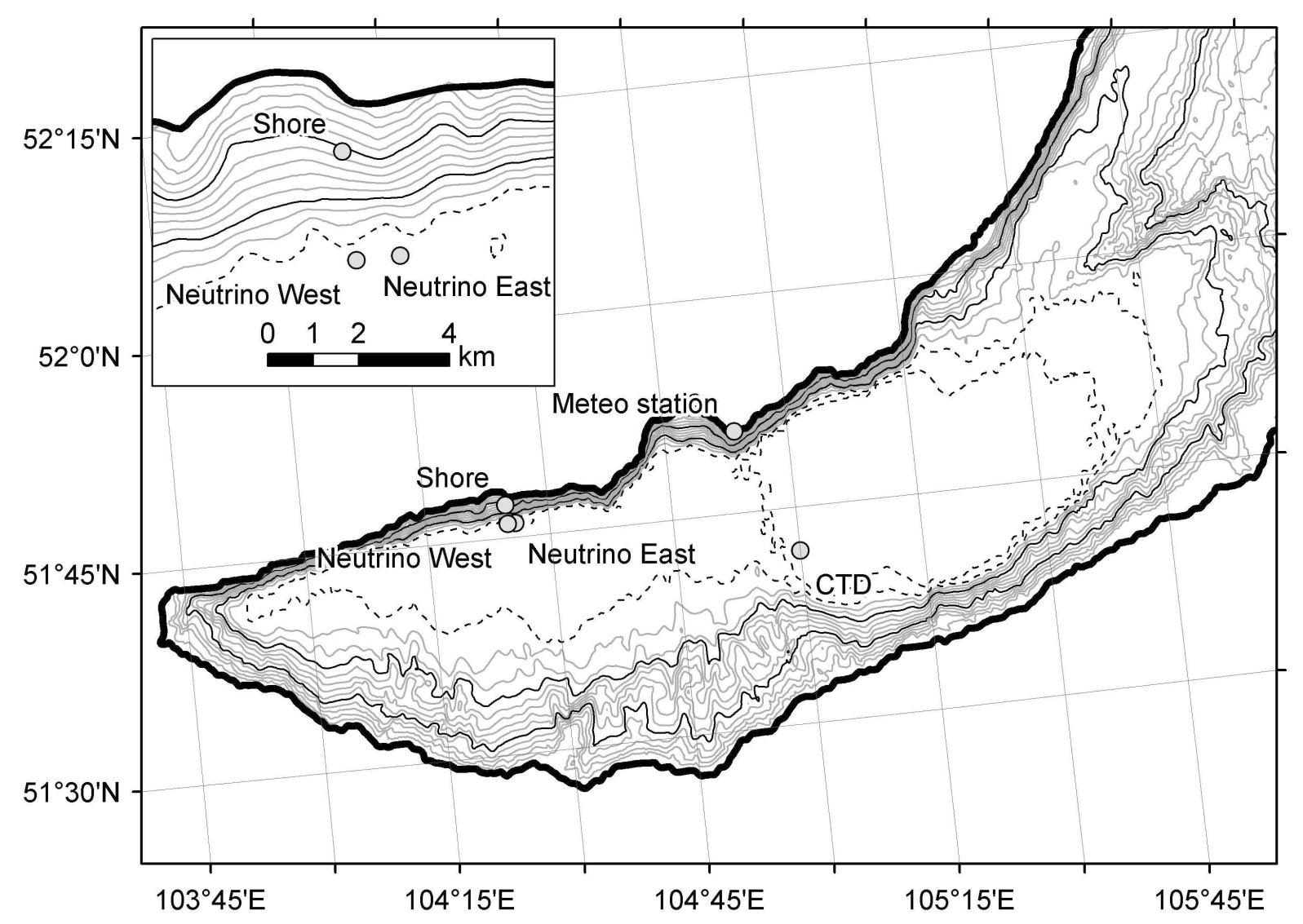

Figure 2. Locations of moorings, meteo station, and CTD profiles used for estimating the heat content changes shown in Figure 3. The bathymetric isolines show depth intervals of $100 \mathrm{~m}$. The darker lines mark intervals of $500 \mathrm{~m}$, the dashed lines mark 1300 and $1400 \mathrm{~m}$ depth.

March of each year and the depth-area relationship of the SB. The heat input in a year without significant intrusions was roughly estimated to $5^{\circ} \mathrm{C} \mathrm{km}^{3}$ (Figure 3 ). The difference to this value was assumed to be cooling due to the deep water intrusion. Further assuming that the lowest temperature observed at the bottom of the NTW mooring was representative for the intruding water masses, estimated intrusion volumes would have been $27,59,51$ and $30 \mathrm{~km}^{3}$ for the winters 2002/03, 2003/04, 2004/05, and 2006/07, respectively. These volumes are lower for the two winters when the lowest bottom water temperature peaks were observed. Since the energy to displace surface water to a depth where thermobaric instability occurs increases with decreasing surface temperature, colder intrusions might actually be expected to have a smaller volume. The calculated volumes are probably underestimates, as the cooling of the layer below $1400 \mathrm{~m}$ depth $\left(28 \mathrm{~km}^{3}\right.$ volume) and of the water masses above $1300 \mathrm{~m}$ depth were not considered. Typical intrusion volumes can therefore be estimated at 50 to $100 \mathrm{~km}^{3}$, which corresponds to $\sim 5 \%$ of the volume affected by seasonal mixing in the SB and is significantly more than the 1 to $10 \mathrm{~km}^{3}$ of previously observed intrusion events [Wüest et al., 2005]. In the following, the large event observed in winter $2006 / 2007$ is discussed in detail.

[18] Starting from 26 December 2006 in the afternoon, a steady easterly wind with an average speed of $3.8 \mathrm{~m} \mathrm{~s}^{-1}$ blew for 6 days (Figure 4). Such winds often occur in the

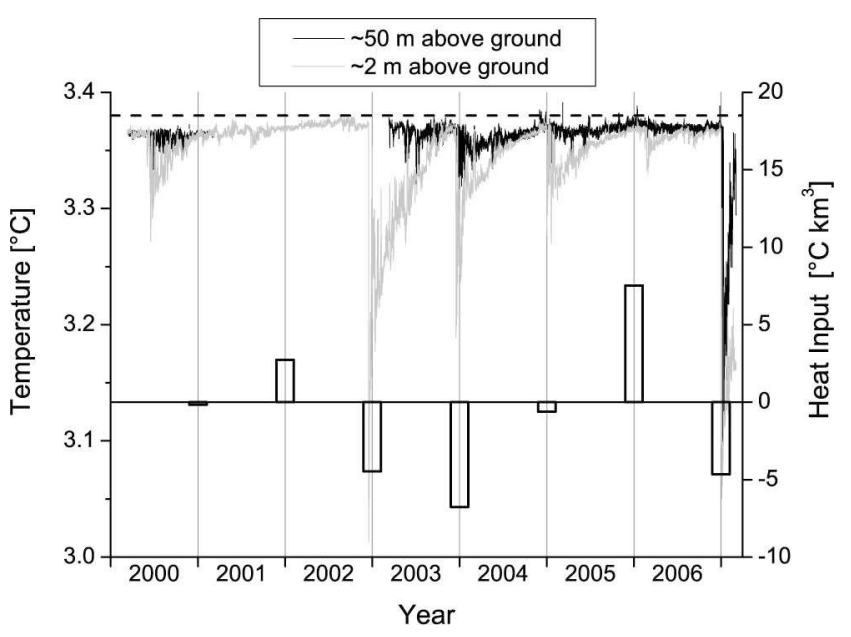

Figure 3. Observed temperatures $2 \mathrm{~m}$ and $50 \mathrm{~m}$ above the bottom at the NTW mooring in the SB from March 2000 to March 2007. The horizontal dashed line indicates the background temperature of $3.38^{\circ} \mathrm{C}$. In 2001 and 2002 the mooring was not equipped with a thermistor $50 \mathrm{~m}$ above bottom. The vertical bars show the change in the heat content (given as the product of temperature and volume) between 1300 and $1400 \mathrm{~m}$ depth from October to March for each winter as calculated from CTD profiles observed at the position marked in Figure 2. 

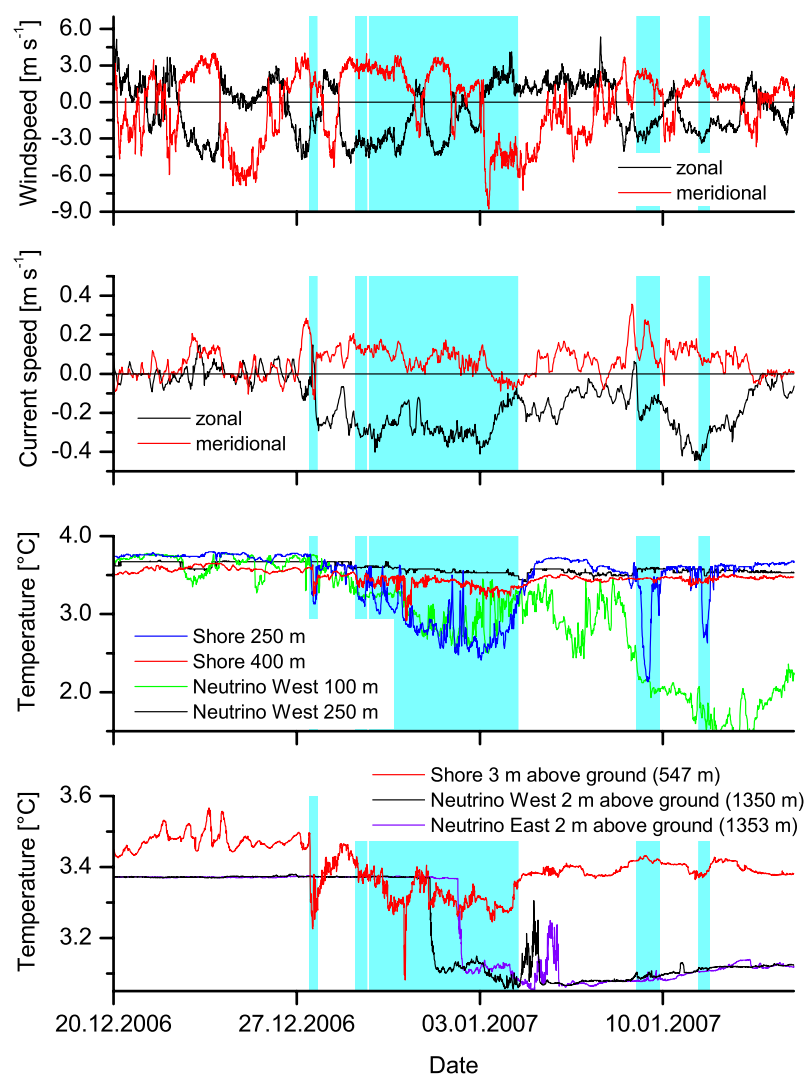

Figure 4. Zonal (along-shore, positive eastwards) and meridional (perpendicular to shore, positive northwards) components of wind speed near Listvyanka and of currents at $16 \mathrm{~m}$ depth at the "Shore" mooring, as well as temperatures observed at different depths at the three moorings. The shaded areas mark the downwelling events when the "Shore" temperature dropped more than $0.2^{\circ} \mathrm{C}$ below the NTW temperature at $250 \mathrm{~m}$ depth.

SB in December and January and are locally called Verkhovik. Although the meteo station was located at a site qualitatively representative of the SB, the wind was probably significantly stronger on the open lake (Figure 2). After one day, the wind resulted in a westward current along the north coast of the SB that lasted until 3 January 2007. The current at $16 \mathrm{~m}$ depth had an average speed of $\sim 0.3 \mathrm{~m} \mathrm{~s}^{-1}$ and caused a strong downwelling along the northern coast. Average monthly temperatures at a given depth at all three moorings usually differ by much less than $0.1^{\circ} \mathrm{C}$, but between 27 December 2006 and 3 January 2007, the temperatures at the "Shore" mooring between 150 and $250 \mathrm{~m}$ depth were about 0.7 to $0.9^{\circ} \mathrm{C}$ lower than the corresponding temperatures at the NTW mooring. The "Shore" temperature at $250 \mathrm{~m}$ depth cooled down to values similar to those at the NTW 100 m depth, whereas the NTW temperature at $250 \mathrm{~m}$ depth remained almost constant (Figure 4). Even at $400 \mathrm{~m}$ depth, a significant cooling was observed at the "Shore" mooring. To our knowledge, such a continuous downwelling exceeding $150 \mathrm{~m}$ has never been observed in Lake Baikal.

[19] Vertically integrating the density difference from 15 to $300 \mathrm{~m}$ depth between the moorings "Shore" and NTW for the time when the current was relatively stable (between
28 December 2006 and 2 January 2007) yields a baroclinic pressure gradient of $3.1 \mathrm{mPa} \mathrm{m}^{-1}$. Assuming a geostrophic flow, i.e. a steady state equilibrium flow driven only by the pressure gradient and the Coriolis force, the along-shore current should have had a speed of $0.27 \mathrm{~m} \mathrm{~s}^{-1}$ at $15 \mathrm{~m}$ depth, which is exactly equal to the average observed westward along-shore component during this time period. The perfect agreement is certainly a coincidence, but it shows that the pressure required to generate the observed downwelling is consistent with the observed horizontal currents. The surface current had also an average component of $0.09 \mathrm{~m} \mathrm{~s}^{-1}$ towards the shore. If this value is representative for a shore length on the order of $150 \mathrm{~km}$ and for the top $50 \mathrm{~m}$ of the water column, a volume of about $350 \mathrm{~km}^{3}$ would have been transported towards the shore, which could easily account for the intrusion volumes calculated above.

[20] On two occasions, the downwelling was strong enough to overcome the potential energy barrier for deep water formation, as can be seen in the "Shore" temperatures observed $3 \mathrm{~m}$ above ground ( $547 \mathrm{~m}$ depth). On 27 December, this temperature dropped from $3.5^{\circ} \mathrm{C}$ to $3.25^{\circ} \mathrm{C}$ within 2.5 hours, and on 31 December from 3.32 to $3.12^{\circ} \mathrm{C}$ within 20 minutes, whereas it had never dropped below $3.35^{\circ} \mathrm{C}$ for more than 2.5 years before. As the TMD is $2.9^{\circ} \mathrm{C}$ at this depth and salinity is negligible for the density stratification in the deep zone of the SB, this cold water was heavier than both the offshore water at the same depth $\left(3.45^{\circ} \mathrm{C}\right)$ and the deep water $\left(3.38^{\circ} \mathrm{C}\right)$, and therefore plunged down the steep slope and reached the maximum depth of the SB. Between 27 December and 3 January, this condition was almost permanently fulfilled, and continuous deepwater formation could be expected. The $3.1^{\circ} \mathrm{C}$ cold water front reached the lowest thermistor of NTW 24 hours later, and that of NTE 50 hours later, which indicates that the front moved eastward with a speed of $\sim 1 \mathrm{~km} \mathrm{~d}^{-1}$.

[21] We conclude that coastal downwelling followed by thermobaric instability caused the large deepwater intrusion in winter 2006/2007. Observations from winter 2004/2005 (not shown) were qualitatively very similar but not sufficient to resolve the mechanism. We therefore suggest that the same mechanism caused all the cold intrusions observed in previous years (Figure 3). This hypothesis is consistent with the fact that the driving force, i.e. the average wind speed in December [Shimaraev et al., 1994], is highest $\left(5.8 \mathrm{~m} \mathrm{~s}^{-1}\right)$ in the $\mathrm{CB}$, where the lowest bottom temperatures and the strongest vertical temperature gradient in the deep water indicate the most efficient deepwater renewal. Conversely, relatively weak winds $\left(4.0 \mathrm{~m} \mathrm{~s}^{-1}\right)$ lead to higher bottom temperatures and a weaker temperature gradient in the NB, while the SB $\left(5.2 \mathrm{~m} \mathrm{~s}^{-1}\right)$ lies in between the two for all three parameters. The same processes might be important in other deep temperate lakes where the temperature curve crosses the TMD. They have actually been suggested as the cause for large deep intrusions observed in Crater Lake, but due to the lack of nearshore data this hypothesis could not be proved [Crawford and Collier, 2007]. Similar intrusions have also been observed in Quesnel Lake (E. Carmack et al., unpublished data, 2003/2004).

[22] Based on this evaluation of the underlying mechanisms, we predict the following sensitivities of deepwater 
renewal to expected environmental changes: A temperature increase of the whole water column by a few tenths of a degree would facilitate deepwater renewal, as the deepwater temperature would move away from TMD. This negative feedback means that the temperature of the permanently stratified deep water is not sensitive to global warming, whereas the rate of bottom water renewal and thus the nutrient recycling could potentially increase. A seasonal shift in water temperatures or a shortening or lengthening of the ice-covered period should have no effect other than changing the timing of deepwater renewal - except if the typical Verkhovik winds in December/January no longer occur at the same time as the optimal conditions for downwelling. Obviously, increasing wind speeds would lead to enhanced deepwater renewal. Recently, the intensity of the wintertime Siberian high has considerably decreased [Panagiotopoulos et al., 2005]. The effect of this trend on the local winds remains to be investigated, but if it leads to a change in the timing or strength of the Verkhovik winds, the consequences for the deepwater renewal could be important.

[23] Acknowledgments. The authors would like to thank J. Chavanne, G.V. Domogatsky, R. Gnatovsky, S. Lovtsov, V.K. Markov, V. Obolkin, A.I. Panfilov, Y.M. Parfenov, M.I. Rosanov, B.A. Tarashansky, E.G. Vologina and A.A. Zhdanov for their invaluable support during field work and fruitful discussions. This research was supported by Eawag research funds (VERTEX), the EU-project CONTINENT, the Russian Foundation for Basic Research, and the Ministry of Education and Science of the Russian Federation.

\section{References}

Akimoto, K., K. Tanaka, T. Awaji, and N. Imasato (1995), Deep convection in a lake triggered by wind: Two-dimensional numerical experiments with a nonhydrostatic model, J. Oceanogr., 51, 171-185.

Crawford, G. B., and R. W. Collier (2007), Long-term observations of deepwater renewal in Crater Lake, Oregon, Hydrobiologia, 574, 47-68, doi:10.1007/s10750-006-0345-3.
Hohmann, R., R. Kipfer, F. Peeters, G. Piepke, D. M. Imboden, and M. N. Shimaraev (1997), Processes of deep water renewal in Lake Baikal, Limnol. Oceanogr., 42, 841-855.

Kipfer, R., M. Hofer, F. Peeters, D. M. Imboden, and V. M. Domysheva (2000), Vertical turbulent diffusion and upwelling in Lake Baikal estimated by inverse modeling of transient tracers, J. Geophys. Res., 105, $3451-3464$.

Kozhova, O. M., and L. R. Izmesteva (1998), Lake Baikal: Evolution and Biodiversity. Biology of Inland Waters, 447 pp., Backhuys, Leiden, Netherlands.

Mackay, A. W. (2007), The paleoclimatology of Lake Baikal: A diatom synthesis and prospectus, Earth Sci. Rev., 82, 181-215.

Müller, B., M. Maerki, M. Schmid, E. G. Vologina, B. Wehrli, A. Wüest, and M. Sturm (2005), Internal carbon and nutrient cycling in Lake Baikal: Sedimentation, upwelling and early diagenesis, Global Planet. Change, 46, 101-124, doi:10.1016/j.gloplacha.2004.11.008.

Panagiotopoulos, F., M. Shahgedanova, A. Hannachi, and D. B. Stephenson (2005), Observed trends and teleconnections of the Siberian high: A recently declining center of action, J. Clim., 18, 1411-1422, doi:10.1175/JCLI3352.1.

Shimaraev, M. N., N. G. Granin, and A. A. Zhdanov (1993), Deep ventilation of Lake Baikal due to spring thermal bars, Limnol. Oceanogr., 38, $1068-1072$

Shimaraev, M. N., V. I. Verbolov, N. G. Granin, and P. P. Sherstyankin (1994), Physical Limnology of Lake Baikal: A Review, 81 pp., Baikal Int. Cent. of Ecol. Res., Irkutsk, Russia.

Todd, M. C., and A. W. Mackay (2003), Large-scale climatic controls on Lake Baikal ice cover, J. Clim., 16, 3186-3199, doi:10.1175/15200442(2003)016<3186:LCCOLB >2.0.CO;2.

Weiss, R. F., E. C. Carmack, and V. M. Koropalov (1991), Deep-water renewal and biological production in Lake Baikal, Nature, 349, 665-669.

Wüest, A., and A. Lorke (2003), Small-scale hydrodynamics in lakes, Annu. Rev. Fluid Mech., 35, 373-412, doi:10.1146/annurev.fluid. 35.101101 .161220

Wüest, A., T. M. Ravens, N. G. Granin, O. Kocsis, M. Schurter, and M. Sturm (2005), Cold intrusions in Lake Baikal - Direct observational evidence for deep water renewal, Limnol. Oceanogr., 50, 184-196.

M. Schmid, M. Schurter, M. Sturm, and A. Wüest, Swiss Federal Institute of Aquatic Science and Technology (Eawag), CH-6047 Kastanienbaum, Switzerland. (martin.schmid@eawag.ch)

M. M. Budnev, Irkutsk State University, Applied Physics Institute, Boulevard Gagarin 20, Irkutsk 664003, Russia.

N. G. Granin, Limnological Institute of the Siberian Division of the Russian Academy of Sciences, P.O. Box 4199, Irkutsk 664033, Russia. 